\title{
Microstructure and Hardness of 2024 Alloy Subject to Hot-Extrusion, Cold-Rolling and Heat-Treatments
}

C.G. Garay-Reyes ${ }^{1}$, J. C. Aranda-Casas ${ }^{2}$, I. Estrada-Guel ${ }^{1}$, H. M. Medrano-Prieto ${ }^{1}$, J. M. MendozaDuarte $^{1}$, M. C. Maldonado-Orozco ${ }^{2}$ and R. Martínez-Sánchez ${ }^{1}$

${ }^{1}$ Centro de Investigación en Materiales Avanzados (CIMAV), Laboratorio Nacional de Nanotecnología, Miguel de Cervantes No. 120, 31136, Chihuahua, Chih., México.

${ }^{2}$ Universidad Autónoma de Chihuahua (UACH), Facultad de Ingeniería, Circuito No. 1, Nuevo Campus Universitario, CP 31125 Chihuahua, Chih., México.

The 2024 alloy exhibits excellent mechanical properties and low density. Therefore, these alloys are considered to be candidates for application in the aerospace industry. In this context, the strength improvement in 2024 alloys which is achieved by combining different processes, such as solid-solution hardening, plastic deformation, and precipitation strengthening, is the focus of several research groups around the world [1]. In this work are evaluate the microstructure and hardening of the 2024 alloy after hot-extrusion, cold-rolling and heat treatment.

The 2024 alloy fabrication was made by conventional direct casting, the melt was degassed with argon gas $(20 \mathrm{psi})$ for $5 \mathrm{~min}$ period and AlTiB was added as grain refiner $(0.13 \% \mathrm{wt}$.$) . 10 \mathrm{~mm}$ in diameter samples were obtained by hot extrusion (HE). The process conditions were extrusion ratio of 16 and 480 ${ }^{\circ} \mathrm{C}$. The solution heat treatment (SHT) was done at $495^{\circ} \mathrm{C}$ for $7 \mathrm{~h}$. Extrued samples were deformed at 5 and $15 \%$ by cold rolling (CR). After deformation a final aging step $\left(195^{\circ} \mathrm{C}\right)$ at several times was realized. The microstructural characterization was done using an optical microscope (OM) ZEISS model Scope A1, a SEM Hitachi model SU3500 and a TEM PHILIPS model CM-200; XRD analyses were performed in a Panalytical X'Pert PRO diffractometer. The mechanical properties were evaluated using hardness test in a LECO LM300AT microhardness tester in accordance with the ASTM standards.

The Fig. 1 shows the microstructure of 2024 alloy after HE and SHT. The microstructure changed of dendritic grains in as-cast condition to equiaxed grains after $\mathrm{HE}$. The spatial distribution of $\mathrm{Cu}-$ rich phases becomes more homogeneous and smaller particles are observed. In addition, after SHT dissolution of $\mathrm{Cu}$-rich phases was carried out. The Fig. 2 shows a) age-hardening curves of 2024 and $2024 \mathrm{HE}$ alloys after CR 5 and $15 \%$; b-c) shows XRD graphs of 2024 and 2024 HE alloys in conditions as cast, as cast $+\mathrm{HE}$, SHT and at the maximum peak during aging.

. For Fig. 2a, it is evident highest hardness value in samples after CR $15 \%$ and an increase in precipitation kinetics in the same samples, which is associated to a higher number density of precipitates due major dissolution of $\mathrm{Cu}$-rich phases and plastic deformation. For Figs. $2 b-c$, it is evident the formation of $\mathrm{Al}_{2} \mathrm{Cu}$ and $\mathrm{Al}_{2} \mathrm{CuMg}$ precipitates, which are responsible of peak hardening. It is concluded that the $\mathrm{HE}$ and $\mathrm{CR}$ generate changes microstructural that improve the hardness of 2024 alloy. Such changes are associates to precipitates characteristics as number density, spatial distribution, size, morphology and spatial orientation.

References:

[1] C.G. Garay-Reyes, L. González-Rodelas, E. Cuadros-Lugo, E. Martínez-Franco, J. AguilarSantillan, I. Estrada-Guel, M.C. Maldonado-Orozco, R. Martínez-Sánchez, J Alloys Compd 705 (2017) p. 1-8. 


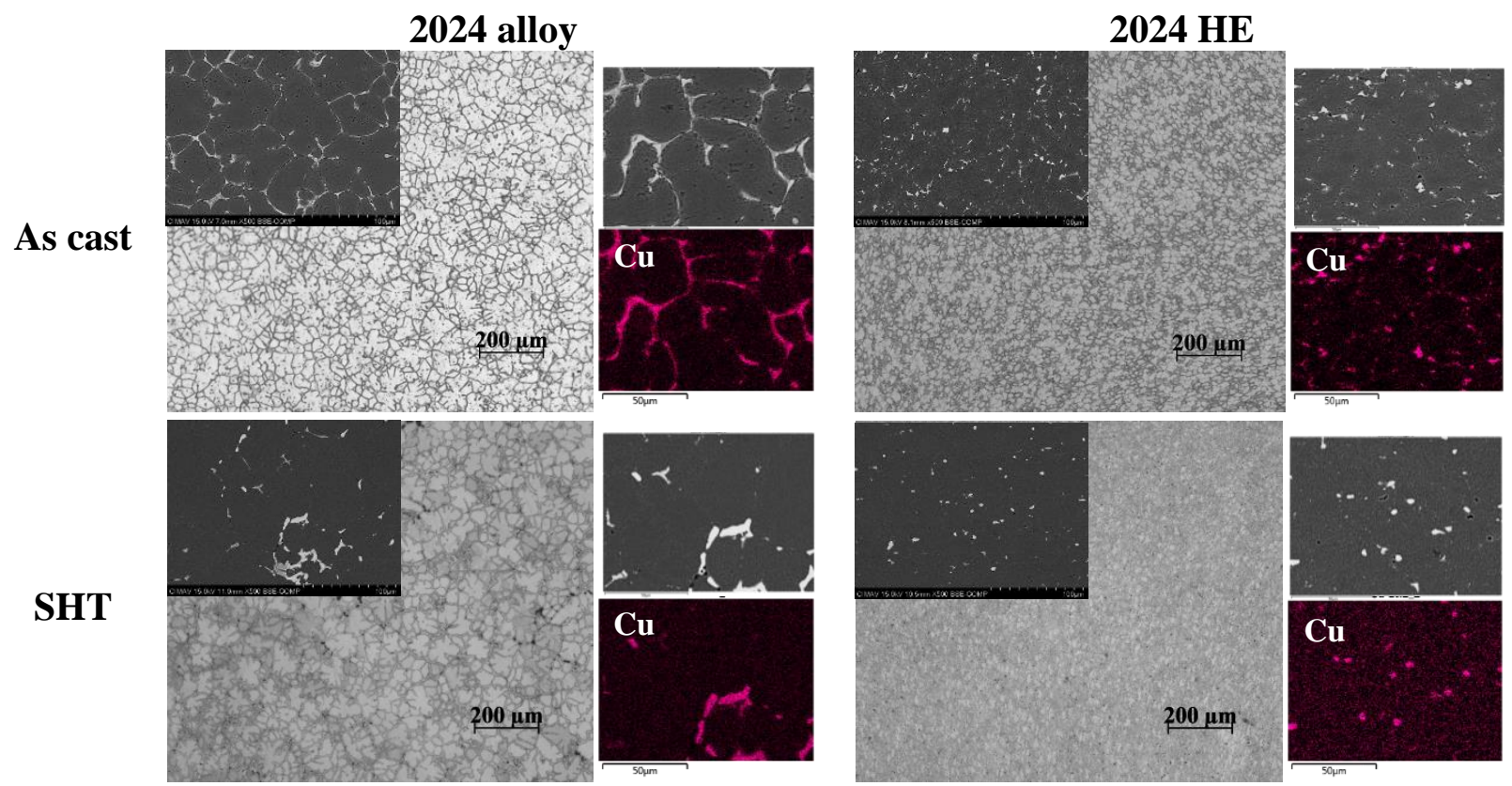

Figure 1. OM-SEM-Maps Micrographs of 2024 and $2024 \mathrm{HE}$ alloys in as cast condition and SHT.

a)
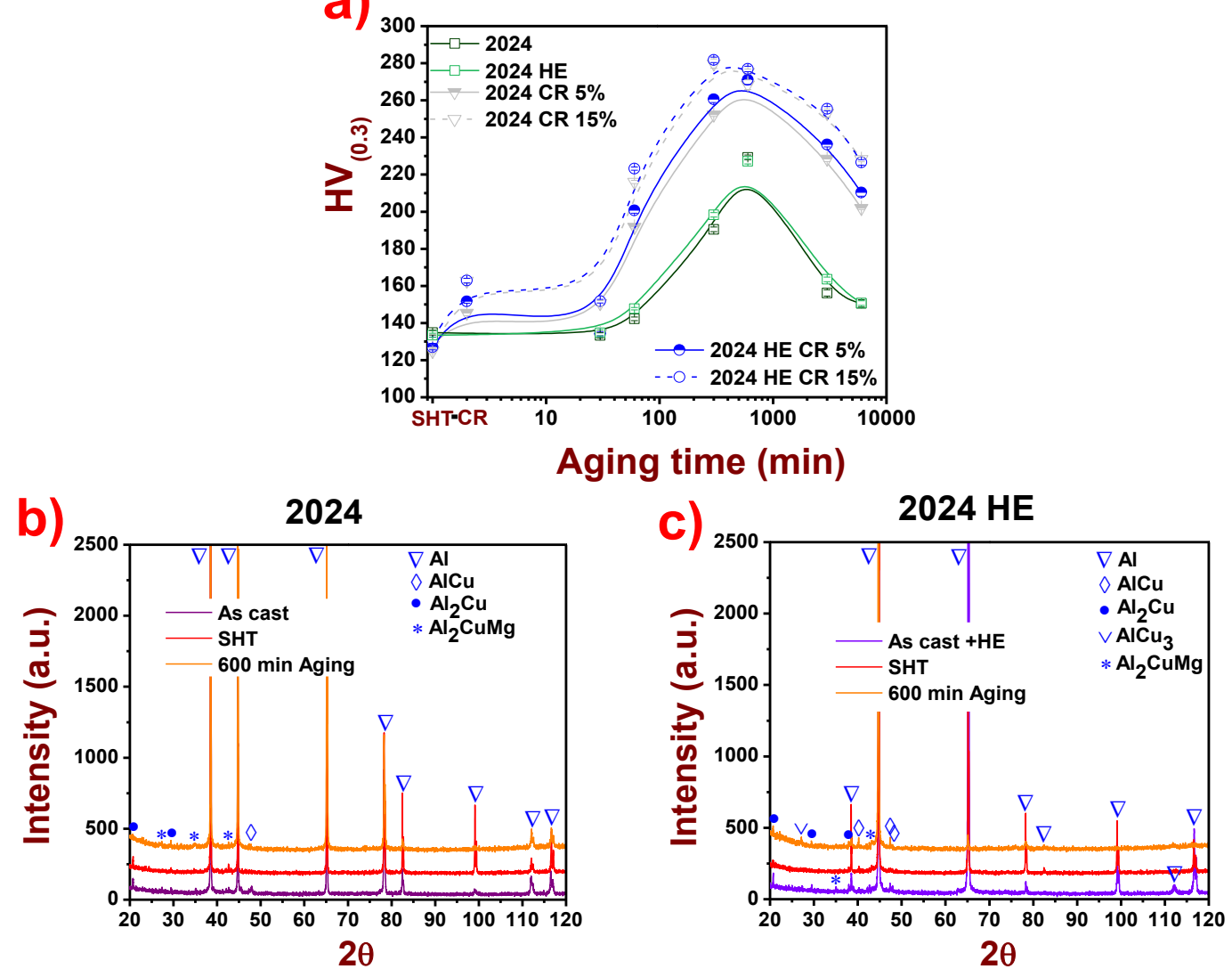

Figure 2. a) Graph of the Vickers hardness (HV) versus aging time and b-c) XRD graphs. For 2024 and $2024 \mathrm{HE}$ alloys, in conditions the as cast condition, as cast + HE, SHT and at the maximum peak during aging. 